\title{
ANÁLISE LEXICAL: A IMAGEM DA MULHER NA REVISTA FEMININA "GRAÇA E BELEZA"
}

\section{ANÁLISIS LÉXICO: IMAGEN DA MUJ ER EN LA REVISTA FEMENINA "GRAÇA E BELEZA"}

\author{
lara Aparecida Garcia \\ Letras (Licenciatura em Português e Espanhol) na \\ Universidade Federal do Triângulo Mineiro (UFTM) \\ Juliana Bertucci Barbosa \\ Universidade Federal do Triângulo Mineiro (UFTM) \\ Mestrado Profissional em Letras (PROFLETRAS) / UFTM
}

Resumo: Neste artigo, acreditamos ser um rico corpus os exemplares de uma revista feminina antiga, da década de 40 , da cidade de Uberaba intitulada Graça e Beleza. Uma das nossas preocupações é entender como as mulheres da década de 40 eram retratadas nessa revista de uma cidade do interior de Minas Gerais, para isso analisamos o léxico empregado, especificamente substantivos, que se referiam à mulher daquela época. Por meio da análise dessas palavras, pudemos verificar que com as transformações, históricosociais podem se refletir no léxico utilizado por uma comunidade. Se considerarmos a dimensão social da língua, podemos ver no léxico o patrimônio social da comunidade, juntamente com outros símbolos da herança cultural.

Palavras-chave: mulher, campo lexical, Uberaba.

Resumen: En este artículo, creemos que es un corpus rico, copias de una revista femenina, de los años 40, de la ciudad de Uberaba titulada Graça e Beleza. Una de nuestras preocupaciones es entender cómo fueron retratados a las mujeres de los años 40 en la revista de una ciudad, en Minas Gerais, para esto se analiza el vocabulario utilizado específicamente sustantivos, que se refería a las mujeres en ese momento. A través del análisis de estas palabras, se observó que con los cambios, histórico-social puede reflejarse en el léxico utilizado por una comunidad. Si tenemos en cuenta la dimensión social del lenguaje, podemos ver la herencia social léxico de la comunidad, junto con otros símbolos del patrimonio cultural.

Palabras-Clave: mujer, campo léxico, Uberaba.

\section{Introdução ${ }^{1}$}

Sabemos que o interesse em estudar épocas passadas é grande, por isso várias áreas de estudos da linguagem buscam entender o que acontece nos dias atuais por meio de estudos de sincronias passadas. Entretanto, um

\footnotetext{
${ }^{1}$ Agência de Fomento: CNPq.
} 
dos obstáculos para quem realiza pesquisas sobre épocas passadas da língua é a da formação de um corpus que contemple uma documentação representativa da época desejada (LABOV, 2008 [1972]). Por isso, neste trabalho, acreditamos ser um rico corpus, exemplares de uma revista feminina antiga, da década de 40, da cidade de Uberaba intitulada "Graça e Beleza".

A partir da seleção desse corpus, uma das nossas preocupações é entender como as mulheres da década de 40 eram retratadas nessa revista, editada e publicada em uma cidade do interior de Minas Gerais. Para isso, analisamos o léxico empregado nessa revista, especificamente os substantivos, que se referiam à mulher daquela época. Justifica-se um estudo lexical, pois o léxico é um elemento que compõe a língua e atua de forma facilitadora retratando as mudanças e variações linguísticas, refletindo assim, as transformações sociais, já que está sempre incorporando unidades linguísticas e/ou ampliando ou restringindo sentidos de significantes já existentes na língua.

Para atingirmos nossos objetivos, inicialmente, neste artigo, refletiremos sobre a relação entre léxico e sociedade. Em seguida, apresentaremos algumas informações histórico-sociais sobre Uberaba da década de 40 e sobre a revista utilizada como corpus. Ao final, resumiremos os procedimentos metodológicos e os resultados relevantes.

\section{Léxico e Sociedade}

A língua funciona como um elemento de interação entre o indivíduo e a sociedade em que ele atua. É por meio dela que a realidade se transforma em signos, pela "associação de significantes sonoros a significados arbitrários, com os quais se processa a comunicação linguística” (PRETI, 2003, p. 12). A língua, assim, pode ser entendida como uma criação da sociedade, ou seja, ela é mutável e está em evolução. Assim, ao estudar a língua, os contextos socioculturais em que ela ocorre são elementos básicos, e, muitas vezes, determinantes de suas variações, explicando e justificando fatos que apenas linguisticamente seriam difíceis ou até impossíveis de serem determinados.

No caso específico do léxico, esta afirmação é verdadeira, pois a visão de mundo, a ideologia, os sistemas de valores e as práticas socioculturais das 
comunidades humanas são refletidos no léxico. Como destaca Barbosa (1993, p.01), o léxico "representa, por certo, o espaço privilegiado desse processo de produção, acumulação, transformação e diferenciação desses sistemas de valores".

Para se apreender, compreender, descrever e explicar a "visão de mundo" de um grupo sócio-linguístico-cultural, o objeto de estudo principal são as unidades lexicais e suas relações em contextos. Para Biderman (1978, p.139), "o universo semântico se estrutura em dois polos opostos: o indivíduo e a sociedade. Dessa tensão em movimento se origina o Léxico".

Assim, nos estudos sobre o léxico que buscam recuperar aspectos sociais e culturais de uma época, fica evidente que o léxico, portanto.

(...), é um dos patrimônios da sociedade, já que nele estão contidos todos os conteúdos linguísticos e não linguísticos, todos os referentes do mundo físico e cultural do presente e do passado. Formado por signos verbais, que são as palavras, é utilizado como instrumento de comunicação, e é transmitido de geração, perpetuando, assim, a herança cultural. (CERÂNTOLA, 2009, p. 36).

Para a autora, todo léxico faz parte do patrimônio cultural das sociedades, porque através do léxico conhecemos a cultura e a realidade de uma determinada época. O que tentamos realizar em nosso estudo é conhecer, por meio do léxico, um pouco da realidade das mulheres da década de 40 da cidade de Uberaba.

\subsection{Campos Lexicais}

A Lexicologia, segundo Bidermam (1978), enquanto ciência do léxico estuda as suas diversas relações com os outros sistemas da língua, e, sobretudo, as relações internas do próprio léxico. Essa ciência abrange diversos domínios como a formação de palavras, a etimologia, a criação e importação de palavras, a estatística lexical, relacionando-se necessariamente com a fonologia, a morfologia, a sintaxe e, em particular, com a semântica.

Os campos lexicais representam uma estrutura, um todo articulado, em 
que há uma relação de coordenação e hierarquia entre os léxicos. Assim, sob essa perspectiva, as palavras são organizadas em um campo com mútua dependência, adquirindo uma determinação conceitual a partir da estrutura do todo. O significado de cada palavra vai depender do significado de suas vizinhas conceituais. Tais léxicos só passam a ter sentido como parte de um todo, pois só no campo terão significação. Assim, para entender a lexia individualmente, é necessário observá-la no seu conjunto de campo, pois fora desse conjunto não pode existir uma significação, uma vez que a mesma só existe nesse conjunto e em sua razão.

Oliveira (2008), complementando essa definição, argumenta que os campos lexicais são grupos de palavras relacionadas entre si por fatores extralinguísticos. Ou seja, trata-se de laços associativos entre palavras consideradas do mesmo campo semântico que podem ser organizadas individualmente, de acordo com o conhecimento que se tem sobre o assunto. Vejamos um exemplo, extraído de Oliveira (2002):

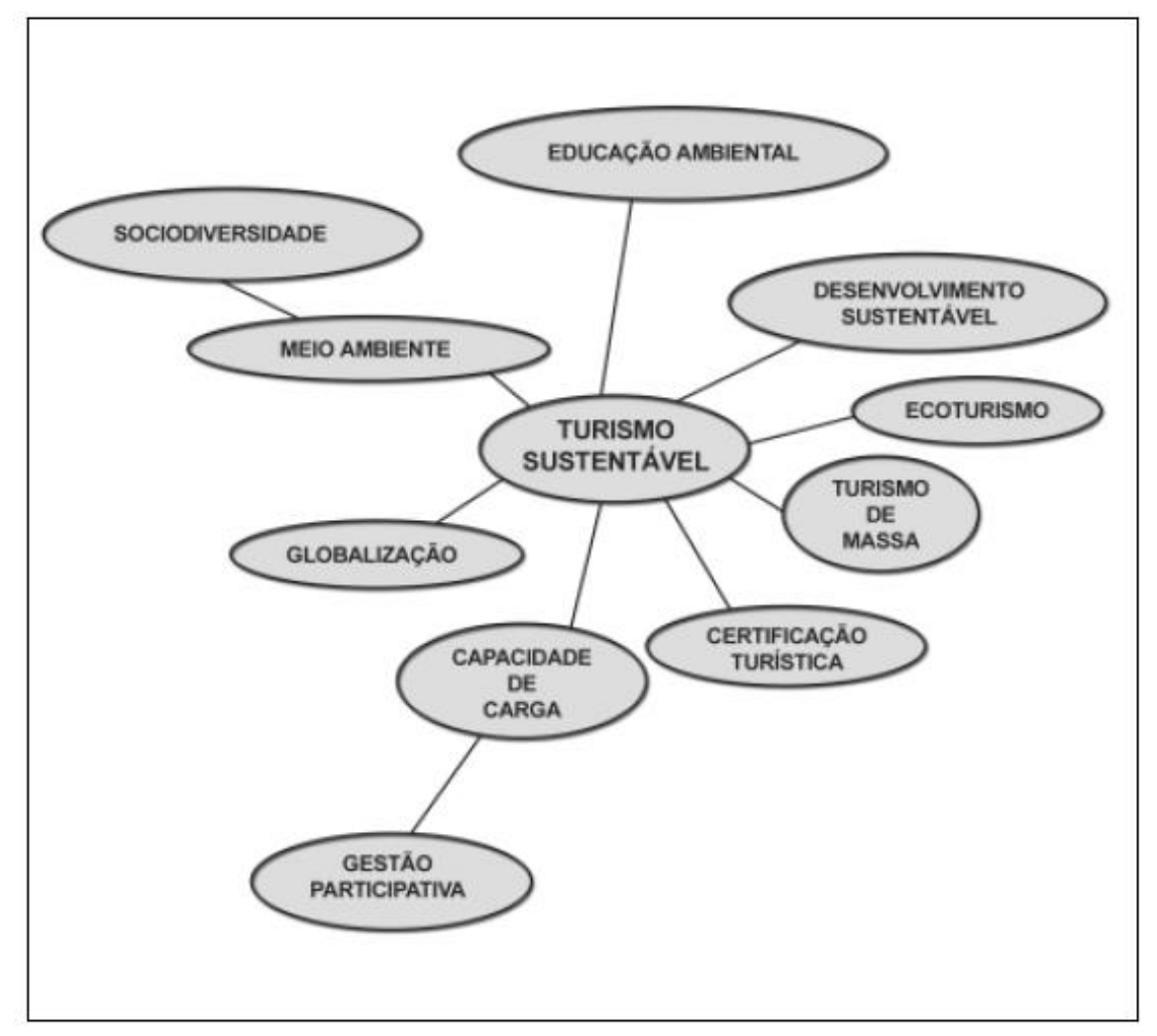

Figura 1: exemplo de campos semântico Fonte: OLIVEIRA, 2002, p. 152. 
Como podemos observar, do campo acima, no qual se centraliza a palavra "Turismo sustentável", irradia outras palavras (lexias) que podem fazer parte dessa rede de relações semânticas, como: educação ambiental, meio ambiente, globalização, turismo de massa, ecoturismo, desenvolvimento sustentável, capacidade de carga, certificação turística, entre outras. Em nosso trabalho a palavra central é "mulher" e a ela uma rede de outras palavras (ou relações semânticas) se ligam: a) sexo/amor; b) o corpo e os membros; c) trabalho; d) casa, e) beleza, f) família, g) roupa, h) estudo.

Para chegarmos aos campos semânticos utilizamos como critérios os resultados da tese de doutora da Cerântola como base da nossa pesquisa. Nos campos que são duplos também foram retirados da mesma pesquisa que utilizamos como base de todo nosso trabalho.

Como podemos observar, o usuário da língua utiliza-a como meio para inferir o "microuniverso" de um autor (ou de uma revista, como é o nosso caso), podendo assim retratar ou recuperar uma parte dos aspectos ideológicos e comportamentais da sociedade em que viveu. Assim, nesta pesquisa, para a aplicação dos campos lexicais associativos, seguimos os fundamentos da análise estrutural semântica.

\subsection{O léxico e os aspectos linguísticos e sociais: resultados de outras pesquisas}

Algumas pesquisas lexicais evidenciaram aspectos linguísticos e sociais de uma época ou de um grupo (comunidade). Entre esses trabalhos, podemos citar o de Cerântola (2009), que por meio da análise, com base na teoria, dos campos lexicais, de substantivos e adjetivos encontrados em exemplares da revista Cláudia, publicados entre os anos de 1961 a 1969, demonstrou como era a imagem da mulher daquela época.

A autora elegeu, assim como fazemos em nosso trabalho, uma revista feminina, pois partiu do princípio que por meio do emprego do léxico utilizado na revista poderia recuperar aspectos da sociedade daquela época. Sobre isso, a autora afirma: "Escolhemos, a revista Cláudia, pois de todas as femininas é a que maior público alcança” (CERÂNTOLA, 2009, p.11). 
Cerântola (2009) coletou para seu corpus seiscentas e sessenta e sete (667) palavras e quase a totalidade - seiscentos e vinte e três (623) pertenciam ao tema (item) B (O Homem do Sistema de Conceitos). Os demais léxicos se encaixavam nos grupos: vinte e oito (28) palavras no grupo A (O Universo) e dezesseis (16) em $C$ ( $O$ homem e o Universo). A autora concentrou seus estudos assim, devido a alta frequência, nas palavras do item $B$.

A pesquisadora destaca algumas lexias, que consideramos relevantes para sua análise, são elas: preconceito; tradição; liberada; desprezada; desrespeitada; independência; independente; evoluída; traição; fechada; prêsa; aprovação; autorização; liberdade. A palavra "tradição" registra um comportamento que ao longo do tempo se repete, pois, embora os jovens peçam para si atitudes diferentes, quando arguidos de como se comportariam com seus filhos na mesma situação, repetem o discurso dos pais. A lexia "preconceito" marca uma das características dessa tradição. Em relação às lexias "liberada, evoluída, independência, independente", Cerântola afirmou que foram utilizadas de forma imprópria, já que não refletiam a ação ou o sentimento de quem a usa. Para a autora, são as jovens que muitas vezes tomam atitudes mais ousadas para a época e depois sofrem com sentimento de culpa. As palavras "independente, independência e liberdade", da mesma forma, são utilizadas por mulheres que, apesar de dizerem que querem ser independentes e terem liberdade, acreditam que nunca terão oportunidade para tanto, pois primeiro são dependentes dos pais e depois do marido.

Dessa forma, Cerântola, por meio do estudo do léxico na revista Cláudia, não só evidenciou a vida, os valores e as crenças relacionados à mulher da época como também realizou uma análise do comportamento feminino brasileiro da década de sessenta.

Outra pesquisa com léxico, também realizada a partir de revistas, foi o de Ribeiro (2012), que por meio do estudo lexical, investigou as gírias utilizadas por adolescentes. A autora, partindo da concepção de que a língua pode marcar um grupo social, apontou que a gíria utilizada pelos adolescentes pretende atingir de forma original as pessoas de fora do grupo, a fim de incorporá-las a ele. Esse léxico, gíria ou jargão, foi entendido pela autora como um conjunto de expressões estilísticas de cunho popular. 
Outro trabalho, de Delgado (2010), apresentou uma análise e a classificação de gírias presentes nas revistas Atrevida, Todateen e Capricho, destinadas aos adolescentes, com a finalidade de mostrar e traçar o perfil de linguagem desse grupo diante do convívio social. Em tal trabalho, a autora comprovou que por meio do estudo do léxico podemos evidenciar a criatividade do falante ao empregar os recursos oferecidos por uma língua. A participação dos leitores no corpus analisado, demonstrou que não só as revistas fazem uso das gírias, já que têm a função de adequá-la ao seu público-alvo, como também, os próprios adolescentes (leitores) que participam dela. A análise do léxico utilizado pelos adolescentes, de acordo com seu aspecto semântico, foi bastante relevante, visto que se pode associar a linguagem desse público aos seus gostos, comportamentos, relacionamentos, enfim a tudo que faz parte do seu cotidiano.

Durante a coleta dos termos, Delgado observou que as gírias advindas do processo de formação por derivação prefixal foram em grande quantidade ocasionadas pelo prefixo - super com 52 gírias; -mega com 8 gírias e uma gíria com o prefixo -ex e outra com o prefixo -des. Um exemplo bastante interessante formado por esse processo foi o "super-hiper-megafavor", o que caracteriza que não é apenas um favor, mas sim, um grande, ou seja, um enorme favor, devido aos prefixos terem o significado de excesso, além. Portanto, os exemplos mencionados na análise mostraram um estudo acerca da criatividade dos falantes da língua materna na formação desses vocábulos, o que nos faz perceber que a gíria vem ganhando um papel na ampliação lexical, principalmente entre os adolescentes, combatendo o tratamento dado a ela de forma preconceituosa.

\section{3. $O$ corpus utilizado: A Revista Graça e Beleza}

Conhecemos a revista no arquivo público, quando fazíamos pesquisas com um jornal da cidade Lavoura e comercio de grande conhecimento circulação da população uberabense. Ficamos fascinadas por saber que acabava de descobrir um tesouro linguístico. Uma revista feminina que foi publicada na década de 40 em uma cidade tão conservadora como Uberaba, sensação incrível gerou muita curiosidade. Ao iniciarmos nossa pesquisa, não 
encontrávamos textos escritos sobre a revista, então procuramos um historiador Guido Bilharinho, da cidade que nos forneceu informações sobre a revista.

Não há registros do período de publicação exato da revista Graça e Beleza. As edições encontradas são equivalentes aos anos de 1942 a 1946. Foi no texto de Bilharinho (2009) que conseguimos algumas informações da revista:

Outubro de 1941- Lançado o primeiro número da revista graça e beleza por Aluísio de Barros, que logo no no 2 a transfere ao Nicanor de Sousa Júnior. (BILHARINHO, 2009 p.68)

Fevereiro de 1942 - Lançado o segundo número da revista Graça e Beleza, dirigida por Nicanor de Sousa Júnior, tendo como redator-chefe em diversos números o escritor Vítor de Carvalho Ramos, contando, ainda, a partir do número 6 ou 7 , com a participação decisiva da jornalista Iná de Sousa, irmã de Nicanor, como secretária-redatora. Com algumas interrupções, motivadas por dificuldades de importação de material em decorrência da segunda Guerra Mundial, a revista é editada até princípios da década de 1950. (BILHARINHO, 2009, p.69)

Os fundadores da revista foram Nicanor de Sousa Júnior (irmão de Iná), e Aníbal Luís Pereira de Sousa, além da grande mulher á frente de seu tempo, Iná de Sousa que tinha como função ser secretária e redatora.

Focalizando a imagem forte feminina da revista, Iná de Sousa, Nabut afirma:

Para a época, não deveria causar surpresa alguma o sucesso de Iná de Sousa na imprensa de Uberaba, fazendo colunismo em jornal e sendo a principal atuante da revista Graça e Beleza. Ela pertence a um dos principais filões da imprensa do Brasil central. Seu avô, Arredio de Sousa, foi simplesmente o editor da joia rara das revistas da região, o Almanaque Uberabense, que começou a sair no final do século passado, atingindo a segunda década deste século. $O$ bom gosto editorial, ilustrado com o que se pode chamar de iluminuras artnouveau. Depois, Iná é filha de Nicanor de Sousa, o homem de frente do jornal O Triângulo. (NABUT 1990 p.5)

Em relação à estrutura da revista, os gêneros textuais que circulavam na eram contos, versos, crônicas, receitas, sociedade e reportagens. Além disso, como Iná era muito conhecida na rádio nacional, à revista possuía uma seção 
voltada para essas celebridades conhecidas no Brasil e no exterior, chamada Hollywood. A relação da Iná de Sousa com as celebridades estava na página Hollywood, no qual trazia reportagem com as celebridades o modo de vestir, alimentar, os hábitos do dia a dia de cada famoso.

Além disso, na revista "Graça e Beleza", em quase todas as edições encontramos informações na contra capa, que nos auxiliaram a entender a revista e, de certa forma, explicavam ao leitores o poderiam encontrar na revista.

Praticamente todas as edições indicavam, na página de rosto, o gênero de revista que o leitor tinha pela frente. Neste número: Contos, Versos, Crônicas, Receitas, Sociedade, Reportagens. (NABUT, 1990 p.5).

Iná de Sousa é quem escrevia nas seções escolhidas para esta pesquisa: "Para Alegrar a Mulher" e "Pagina das mãezinhas". Percebemos, em nossas investigações sobre a revista, que a seção "Pagina das mãezinhas" foi desmembrada através do tempo incialmente fazia parte da página "Para Alegrar a Mulher". Já a seção "Para Alegrar a Mulher" pouco sofreu transformações, apenas algumas ligadas à formatação, como mudança de imagens há edições que não possuem imagens somente escrita.

$\mathrm{Na}$ Graça e Beleza ela assina colunas permanentes diversificadas e denominadas "Pagina das mãezinhas", "No Mundo dos Livros", "Receitas Para Você", "Para Alegrar a Mulher", uma maneira de estar ligada ao lar-doce-lar, mas também às coisas que tramitavam pelas cidades que queriam disfarçar seus perfis provincianos e adquirir ares de metrópole. E é justamente isto que tenta, e quase sempre consegue a revista Graça e Beleza, ao delimitar, mas também, principalmente, ao abrir espaço e vazão para registrar, com competência, a vida ilustrada de uma mulher chamada Iná de Sousa (NABUT, 1990 p.10).

O autor Nabut, faz um panorama histórico da revista e a importância de uma revista do interior do país ter a mesma qualidade das grandes revistas no contexto nacional. Esta qualidade esta ligada as suas fotos as reportagens que possuía temas relevantes para época. 


\subsection{0 contexto histórico da revista: Uberaba na década de $\mathbf{4 0}$}

A cidade de Uberaba, na década 40 , possuía problemas na área da saúde e de infraestrutura, como exemplos temos casos de febre tifoide e falta de saneamento do esgoto. Muitos artigos de jornais da época retratam os chiqueiros em meio à cidade que favorecem o surgimento de várias doenças. Outras doenças da época eram a tuberculose, a paralisia infantil e a hanseníase.

Momento muito importante, em Uberaba, foi o ano de 1940, principalmente no mês de julho, em que ocorreu a grande prova de automobilismo "Getúlio Vargas", que teve como vencedor um argentino. No início de 1941, foi inaugurado os dois maiores e mais importantes cinemas que a cidade já pode admirar, porém hoje já fechados ("Empresa Cinematográfica São Luís", "Cine Metrópole"). Na época, tais cinemas foram considerados os mais luxuosos e confortáveis do Brasil.

Em relação à economia, desde aquela época (aos dias atuais) o que orientava a economia local era o gado zebu:

Refletindo o período do apogeu do gado zebu, inaugura-se, no ano de 40, ao lado do parque Fernando Costa o Cassino da Exposição, que, no entanto, somente funciona neste e no ano seguinte, apresentando, além de jogos de bacará e roleta, festas, eventos beneficentes, bailes e espetáculos com artistas de renome. (BILHARINHO, 2009, p.67)

Neste mesmo ano inaugurou ainda a sociedade Rural com uma imponente sede, fazenda modelo cujo objetivo era estudar raças zebuínas de origem indiana. No ano de 1942, em abril, foi inaugurado o aeroclube de Uberaba, e a cidade de Goiânia que passa ser a nova capital de Goiás, fundado o instituto dos cegos do Brasil Central.

Em agosto o governo brasileiro emite declaração de guerra contra a Alemanha e a Itália, com intensa repercussão na cidade. Soltam - se fogos, nas ruas são tomadas por numerosas manifestações, as lojas e indústrias fecham suas portas, as aulas são suspensas, saindo os alunos do Diocesano às ruas sob gritos de "Guerra", "Abaixo o Eixo", etc... Finalizando tudo em grandioso comício na praça Rui Barbosa. (Bilharinho, 2009, p.73) 
É também na década de 40 que é instituída como a nova moeda do país o cruzeiro, que substitui. (para tirar). No mesmo ano chega para ficar até os dias atuais o refrigerante mais famoso do mundo: a Coca-Cola. É nesse panorama local e nacional que a revista Graça e Beleza "vive" em Uberaba.

\section{Procedimentos Metodológicos}

Para realizamos esta pesquisa, digitalizamos os exemplares da revista Graça e Beleza que estavam no Arquivo Público da cidade de Uberaba e pesquisamos informações sobre a revista. Para atingirmos o objetivo da digitalização, e assim também contribuir para a conservação do patrimônio histórico da cidade de Uberaba, pois as revistas estavam armazenadas em caixas, de forma inadequada, percorremos algumas etapas. Inicialmente:

1) Tirávamos fotos da revista em alta qualidade, com uma máquina profissional;

2) Em seguida, editávamos a imagem com o auxilio de um software editor de imagens;

3) Por fim, transformávamos cada edição da revista em um arquivo em PDF.

Posteriormente, com parceria do Arquivo Público de Uberaba e apoio da FAPEMIG, fizemos a digitalização de todas as revistas com os maquinários adquiridos através do projeto "Hemeroteca Digital". Nessa etapa, passamos a

I) utilizar o scanner importado para digitalizar as revistas;

II) trabalhar com os chips (que auxiliavam nas metragens das páginas, para que todas ficasse iguais, do mesmo tamanho);

II) gerar arquivos PDF automaticamente do scanner.

Após esse longo processo de digitalização, escolhemos para a nossa análise duas seções da revista: "Para alegrar a mulher" e "Páginas das mãezinhas". Nessas seções ${ }^{2}$, selecionamos os substantivos que se referiam à mulher ou ao seu universo (ações do cotidiano da época), em seguida os

\footnotetext{
${ }^{2}$ Por uma questão metodológica (pois muitos léxicos se repetiam), trabalhamos apenas com uma edição da revista por ano, no período de 1942 a 1946.
} 
analisamos de acordo com o campo associativo (campo lexical) a que pertencem. Assim, nossa metodologia consistiu em:

(I) selecionar substantivos que se referiam à mulher nas duas seções da revista;

(II) entender quais seriam os semas da palavra, por meio da definição contextualizada e a definição no dicionário;

(III) separar os substantivos por campo lexical, tais palavras: a) sexo/amor; b) o corpo e os membros; c) trabalho; d) casa, e) beleza, f) família, g) roupa, h) estudo.

Dessa forma, seguimos a metodologia proposta por Cerântola, descrita anteriormente. Utilizamos ainda algumas tabelas para facilitar nossas análises e controle dos dados, como o modelo abaixo:

\begin{tabular}{|l|l|l|l|l|l|}
\hline Palavra & $\begin{array}{l}\text { Definição } \\
\text { revista }\end{array}$ & Local & $\begin{array}{l}\text { Definição do } \\
\text { dicionário } \\
\text { século XXI }\end{array}$ & Local & $\begin{array}{l}\text { Campo } \\
\text { semântico }\end{array}$ \\
\hline & & & & & \\
\hline
\end{tabular}

Tabela 1: amostra de tabela utilizada para análise dos dados

Fonte: as autoras

Assim, por meio de analise quati e qualitativa sistematizamos os dados em tabelas e interpretamos a "visão" sobre a mulher, ou seja, sua imagem, na década de 40 na revista Graça e Beleza.

\section{Análise dos dados}

Após a montagem do nosso corpus, selecionamos 273 substantivos que se referiam à mulher ou ao universo da mulher. Tais palavras foram separadas semanticamente em campos lexicais. Em relação à seção "Página da mãezinha", chegamos aos seguintes resultados: 
Revista InterteXto / ISSN: 1981-0601

v. 9 , n. 2 (2016)

\begin{tabular}{|c|c|}
\hline Cuidado/sentimento & 1 \\
\hline Doença & 1 \\
\hline Roupa & 1 \\
\hline Trabalho & 1 \\
\hline Saúde & 2 \\
\hline Higiene & 3 \\
\hline Sentimento & 4 \\
\hline Casa & 21 \\
\hline Estudo & 9 \\
\hline Tempo & 11 \\
\hline O corpo e os membros & 14 \\
\hline Alimentação & 17 \\
\hline Família & 20 \\
\hline Total & 105 \\
\hline
\end{tabular}

Tabela 2: campo lexical da seção "Página da mãezinha"

Fonte: as autoras

Graficamente, temos:

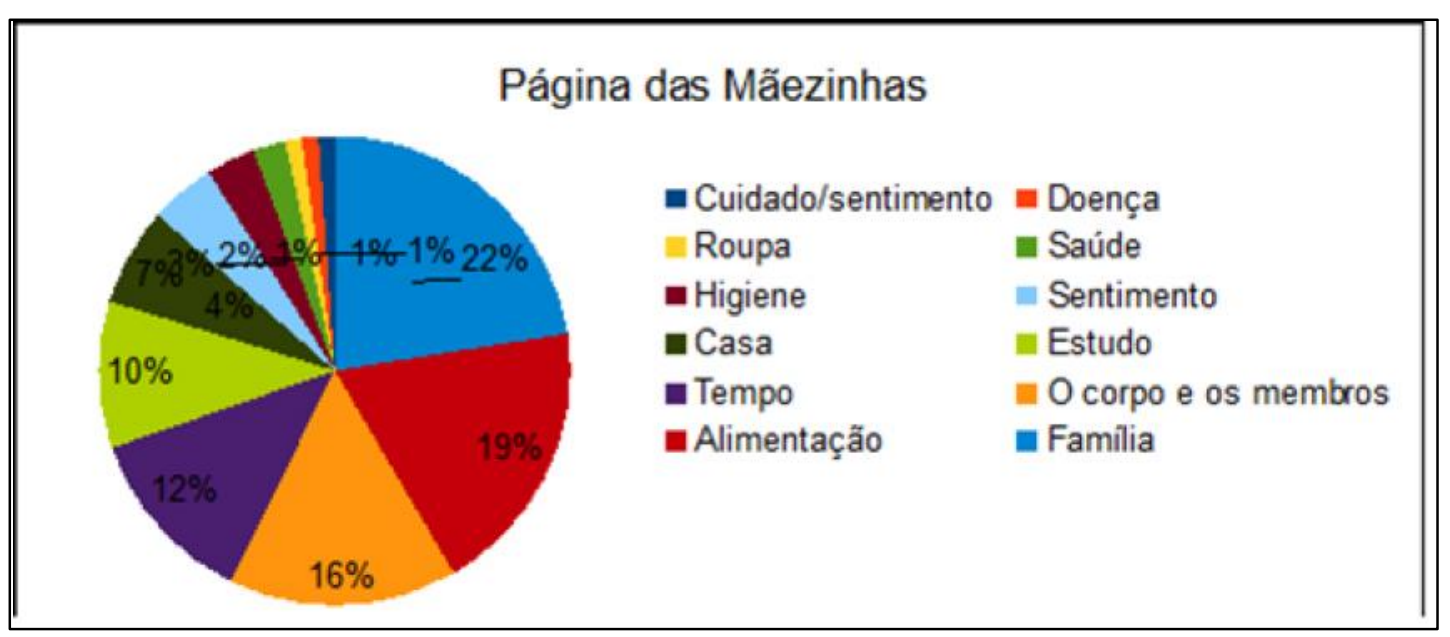

Gráfico 1: campos lexical da seção "Página da mãezinha" 
Na Tabela 2 e no Gráfico 1 acima, podemos observar que na "Página da mãezinha", os substantivos relacionados à mulher estão associados predominantemente aos campos semânticos "família", "casa" e "alimentação", ou seja, nessa seção predomina a visão da mulher como a "dona de casa", que cuida somente da família, dos filhos e do marido. Está mulher já teria várias obrigações com essas tarefas, pois, não e fácil cuidar da casa e de toda família.

Vejamos alguns exemplos:

\section{Conselhos ás mãezinhas}

Pequenas negligencias preparam, por vezes, grandes males. Vigie seu filhinho. Só você mesma poderá evitar-lhe uma grande porção de aborrecimentos; de incidentes, de acidentes.

Figura 1: Graça e Beleza; PM; 1942; dez; p.37.

Nesse fragmento, vemos que o próprio título, "conselho para mãezinha", remete a dicas para que as mães não errem na educação. Na segunda oração, observamos o substantivo filhinho, ligado a palavra "mãe" além do substantivo acidente referindo-se ao cuidado com filhinho, para que nada de errado e grave ocorra. Na década de 40 as mulheres eram tratadas como sexo frágil, por isso à responsabilidade que tinham era somente de cuidar da família, pois, não podiam trabalhar. (tem algumas expressões como: cuidado sentimento? Família/ infantilização discutir /preservação da vida/ so você / dar a vida/ )

Outro exemplo: 


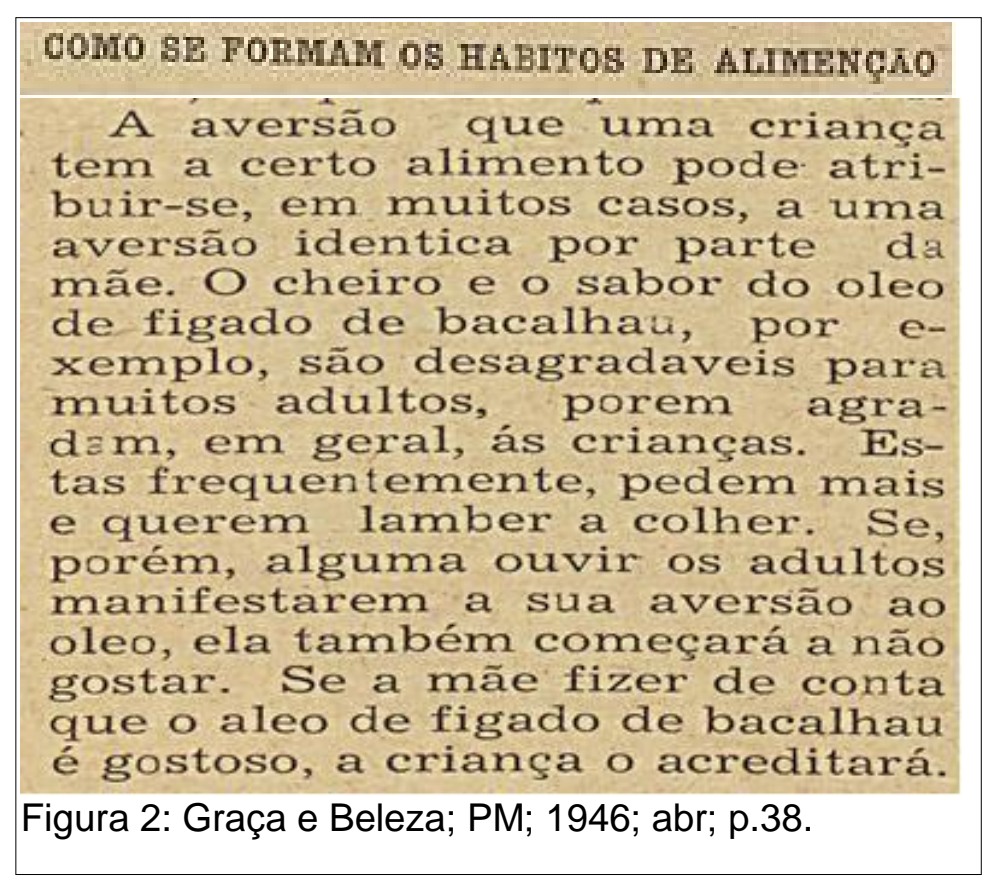

Na Figura 2, temos o campo semântico e o tema da "alimentação", em que a mulher é a única responsável pela criança não gostar de determinados alimentos. Ou seja, a imagem da mulher está ligada à figura "materna", responsável por tudo que ocorre com a alimentação dos filhos.

Já analisando a seção, "Para alegrar a mulher", temos os seguintes resultados dos campos lexicais mais presentes:

\begin{tabular}{|c|c|}
\hline Campo semântico & Número de Ocorrências \\
\hline Casa & 0 \\
\hline Cuidado/sentimento & 0 \\
\hline Trabalho & 1 \\
\hline Doença & 2 \\
\hline Higiene & 2 \\
\hline Saúde & 3 \\
\hline Sentimento & 3 \\
\hline Roupa & \\
\hline
\end{tabular}




\begin{tabular}{|c|c|}
\hline Tempo & 7 \\
\hline Alimentação & 8 \\
\hline Sexo/amor & 9 \\
\hline Estudo & 31 \\
\hline Família & 18 \\
\hline O corpo e os membros & 23 \\
\hline Beleza & 30 \\
\hline Outros & 33 \\
\hline Total & 168 \\
\hline
\end{tabular}

Tabela 3: campo lexical da seção "Para alegrar a mulher"

Fonte: as autoras

Estatisticamente, temos o seguinte resultado:

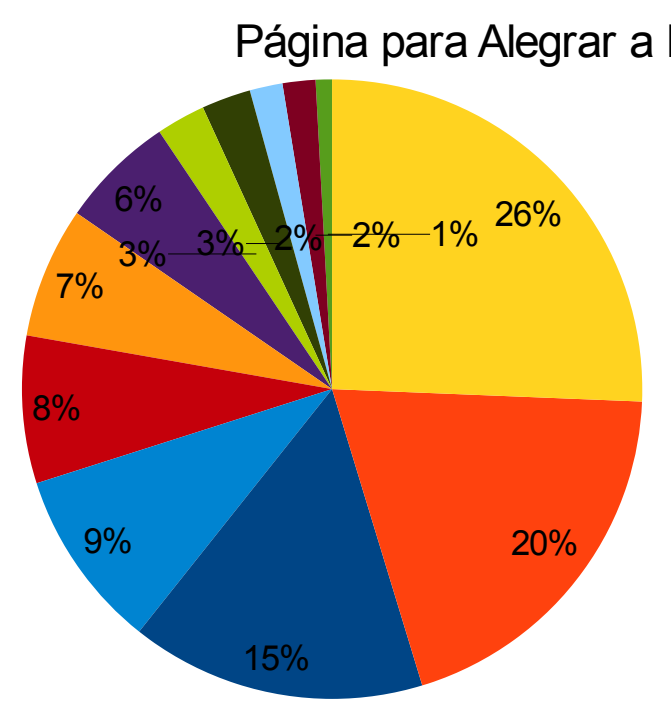

Casa

Cuidado/sentimento

- Trabalho

Doença

- Higiene

- Saúde

- Sentimento

Roupa

- Tempo

Alimentação

- Sexo/amor

- Estudo

- Família

O corpo e os membros

Beleza

Gráfico 2: campo lexical da seção "Para alegrar a mulher" Fonte: as autoras

Nessa seção, "Página Para Alegrar a Mulher", temos indícios da imagem da mulher um pouco mais associada a outros valores, a uma mulher um pouco 
mais "avançada" para seu tempo. Nessa seção já podemos ver a imagem da mulher ligada ao "estudo" e ao "trabalho", algo que não acontece na seção "Página da mãezinha". Algumas vezes, aparecem ainda conselhos amorosos, ou para que a mulher invista em seus estudos.

Observemos alguns exemplos:

A mulher de hoje sabe trabalhar!
A mulher de hoje sabe pensar !
Tudo isto, faz a mulher de hoje!
A mulher de hoje, não é mais aquele sexo fragil e
delicado de antigamente, mas é um exemplo vivo de que
não só o homem sabe trabalhar e lutar para vencer !
A mulher de hoje, sabe trabalhar, sabe lutar, sabe,
por fim, ser mulher!
Figura $3:$ Graçae Beleza; PAM; $1942 ;$ dez; $p .34$.

Neste trecho, podemos notar a importância para esta escritora de intensificar a frase "mulher de hoje", tenta mostrar que apesar de estar na década de 40, poderiam começar quebrar as barreiras de uma sociedade machista. A escritora buscou evidenciar que as mulheres possuem "capacidade como os homens" para assumir trabalhos fora do lar. O universo do lar não cabe mais para essas mulheres, elas querem mostrar que são capazes de cuidar do lar, dos filhos, da família e ainda ter uma vida profissional.

Outro fragmento:

- "Quero esquecê-lo, mas acho que é impossivel, pois amo-o demasiadamente...", foi como se expressou Mary Lou, de Pstrocinio, em sua delicada eartinha, na qual pede-me gentilmente que lhe indique o mais certo a fa:er na situação em que se acha.

Em sua idade, Mary Lou, 17 anos apenas, isto é exagero de sua parte. Agora é que Você vae começar a viver, e por isso tire esse amor louco dessa cabecinha que está agindo tão erradamente.

Procure um que the queira de verdade, um que a considere acima de todos os prazeres e frivolidades, e sei que no futuro será feliz.

Mostre a ele, com superioridade, que não há um só homem no mundo, e que portanto não lhe faz falta o seu amor fingido.

Nsda é impossivel, querida amiga, quando há força de vontade e pertinacia. Procure esquecê-lo o mais depressa possivel, divirta-se, converse com tódos os rapazes, e, quem sabe, talvez ele sinta um pouquinho de despeito e vá procura-la novamen- 
Figura 4: Graça e Beleza; PAM; 1944, nov p.34:

Nesse fragmento, vemos uma mulher não submissão ao homem, temos palavras do campo lexical da razão: "cabeça", ("siga a cabeça e não o coração"), além de adjetivos como "inteligente", "esforçada", estudiosas". Já nesse outro exemplo:

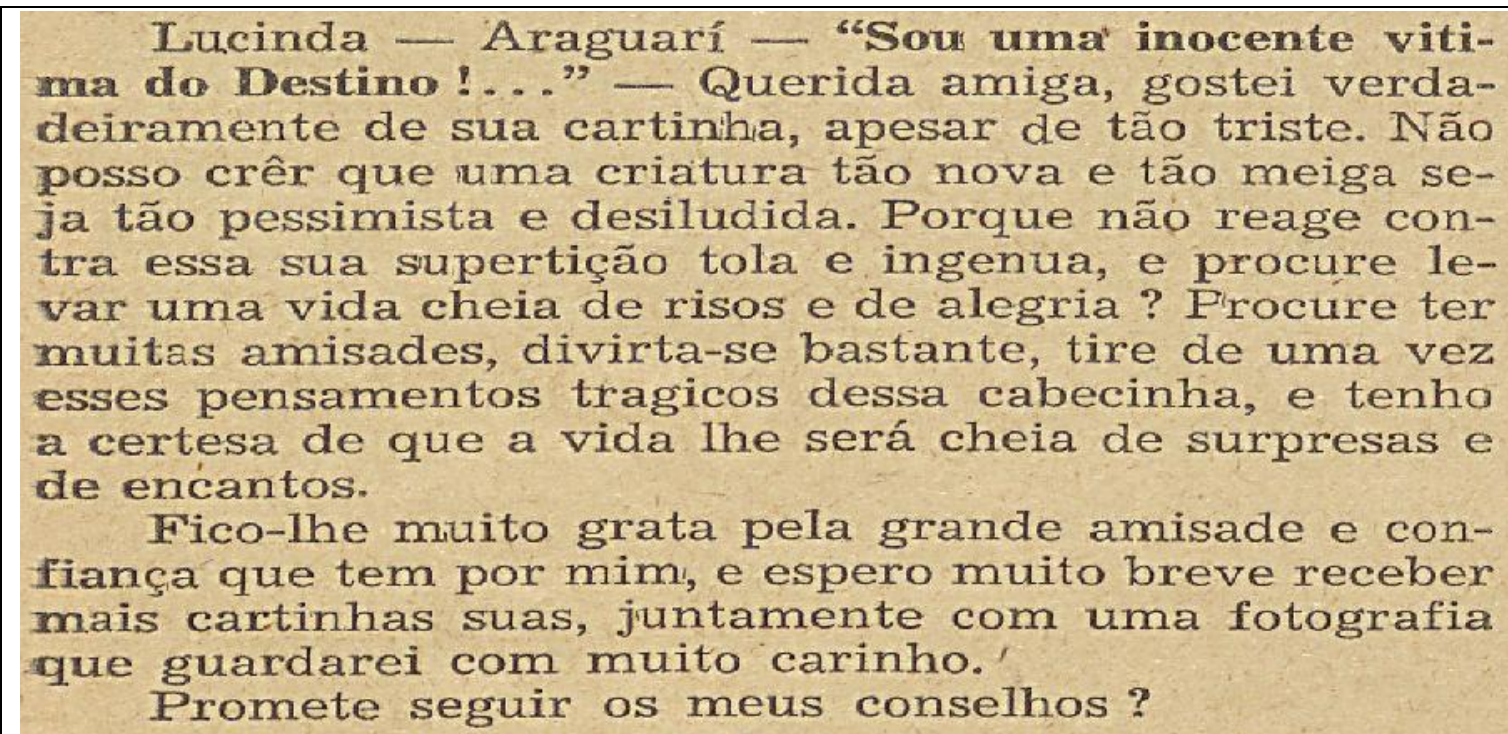

Figura 6 Graça e Beleza; PAM; 1945; fev; p.30.

Observamos que nesse exemplo, Iná aconselha a mulher a fazer "amizades" (outro campo lexical que aparece nessa seção). Não há conselhos sobre casamento, ter filhos, como cuidar da casa, como ocorre na outra seção da revista. A editora sugeriu para que a leitora "curta a vida".

Por fim, outro fragmento que caracteriza o caráter inovador, da revista é: 
$\mathrm{Na}$ atualidade, em que o mundo é um cenario vivo de Iutas, de dôres e de aflições, não só os homens ocupam e têm um lugar de destaque e de ação. A mulher também sabe agir, sabe lutar, sabe trabalhar energicamente pela ordem e pela paz.

Figura 7 Graça e Beleza; PAM; 1942; dez; p.34.

Neste exemplo, temos uma alusão ao momento de guerra que vive o mundo. Porém, relacionado à mulher, além de palavras do campo lexical de "luta" e "dor" (que entrou em "outros", por haver poucas ocorrências), podemos observar ainda verbos de ação (geralmente associados à imagem masculina) como "agir, lutar, trabalhar", que não eram comumente ligadas à imagem da mulher na década de 40. Cerântola (2009), como mencionamos anteriormente, que analisou léxicos na revista Cláudia, da década de 60, encontrou poucas palavras dos campos lexicais "estudo", trabalho" e "luta" relacionadas à figura da mulher. Isso prova mais uma vez que a revista Graça e Beleza, em alguns momentos, conseguia agir à frente do seu tempo.

Cabe lembrar que no século $\mathrm{XX}$, depois das grandes guerras mundiais, dos avanços científicos e tecnológicos, surge a possibilidade de outro espaço para a mulher. Foi justamente por volta da década de 40 que o feminismo dá seus primeiros passos, e com isso começa a pensar na possibilidade de um futuro diferente daquele que the reservaram culturalmente e historicamente. Cabe mencionar que as mulheres já vinham em um processo lento e gradual de conquistas sociais, econômicas e jurídicas, mas é a partir de então que se intensificam as discussões e lutas pela superação da situação das mulheres (social e politica). Essa é um pouco a imagem de mulher que a Iná Sousa, por meio da seção "Página Para Alegrar a Mulher", tenta passar as mulheres de Uberaba e região.

Além dos estudos dos campos lexicais, por meio dos estudos dos léxicos podemos ainda constatar as alterações e/ou recontextualizações lexicais que as palavras sofrem (TARALLO, 1997). É importante destacar que recontextualização de palavras (BORBA, 2003) ou reutilização de palavras já existentes é um dos processos mais produtivos da língua, já que "as palavras 
que apresentam novos significados tornam-se, deste modo, polissêmicas, constituindo a polissemia um dos factores que mais contribuem para economia dos sistemas linguísticos" (CORREIA; LEMOS, 2005, p.47). Exemplo: palavra "farinha" que, no texto, significa um pó branco para embelezar a mulher.

\section{Considerações finais}

Por meio deste estudo, buscamos não só auxiliar na reconstrução da sócio-história do Português Brasileiro, como também contribuir na montagem de corpus em sincronias passadas do Português Mineiro da região de Uberaba.

O estudo lexical realizado na revista Graça e Beleza permitiu-nos conhecer um pouco da cidade de Uberaba da década de 40 e de algumas de suas "pessoas" públicas, a editora da revista, Iná de Sousa. Percebemos que essa revista feminina ao mesmo tempo em que retrata a mulher "dona de casa", "mãe/cuidadora de família", também abre espaço para um "nova" mulher, que pode trabalhar e cuidar de si mesma. Considerando o contexto da cidade de Uberaba, podemos afirmar que era uma revista com traços para "frente do seu tempo".

Além disso, é importante ressaltar que um estudo estrutural do léxico deixa claro que, ainda que não se possa abarcar todo o léxico de uma língua, pode-se começar a realizar a estruturação desse léxico a partir de um corpus delimitado. A teoria dos campos lexicais (da semântica estruturalista) nos dá a possibilidade de realizar um levantamento de um grupo de léxicos específicos e, consequentemente, poder conhecer algum aspecto específico da sociedade em que se está realizando tal estudo. Não pretendemos aqui esgotar este assunto, mas chamar atenção de novos estudos no campo da lexicologia. Estudos esses que se aventurem na história de uma comunidade a partir o seu léxico.

\section{Referências}

BARBOSA, M. Aparecida. O léxico e a produção da cultura: elementos semânticos. I Encontro de estudos linguísticos de assis. Anais. Assis; UNESP, 1993. 
BIDERMAN, M. T. Teoria linguística: linguística quantitativa e computacional. Rio de Janeiro: Livros Técnicos e Científicos, 1978.

BILHARINHO, G. Uberaba: dois séculos de historia. Guido Bilharinho.Uberaba: arquivo Público de Uberaba, 2009. V.2:il...conteúdo: V.2 janeiro 1930 a dezembro 2007 1. Uberaba. Historia. I. Titulo.

BILHARINHO, G. Lavoura e Comércio.Uberaba, terça-feira 25 de janeiro 2000 na coluna "Historia e Cultura".

BORBA, F. S. Organização de dicionários: uma introdução à lexicografia, São Paulo: UNESP, 2003.

CERÂNTOLA, J. R. G.. Cláudia: Um retrato de mulher via léxico. UNESP Araraquara 2009.

CORREIA, M., L. S. P. LEMOS. Inovação lexical em português. Lisboa: Colibri, 2005.

LABOV, W. Padrões Sociolinguísticos. São Paulo: Parábola Editorial, 2008 [1972].

NABUT, J. A. A vida ilustrada de Iná de Sousa. In: Jornal da Manhã. 21 de janeiro 1990.

OLIVEIRA, L. A. Manual de Semântica. Petrópolis, RJ : Vozes, 2008.

OLIVEIRA, L. A. Mapeamento semântico do turismo sustentável (arquitetando um novo país). Prêmio Sesc-Senac de Turismo Sustentável: 2002. Disponível em: http://www.senac.br/informativo/BTS/301/boltec301b.htm. Acesso em 18.10.2015.

PRETI. D. Léxico na língua oral e na escrita. São Paulo:

Humanitas/FFLCH/USP, 2003.

RIBEIRO, S. N. Um estudo sobre o vocabulário das revistas destinadas aos adolescentes. 2012. Disponível em: <

http://www.filologia.org.br/ixcnlf/12/04.htm >. Acesso em: 01 set. 2015.

TARALLO, F. A pesquisa sociolinguística. São Paulo: Ática, 1997. (Série Princípios)

\section{Links consultados:}

- Disponível em: http://www. Vitualbooks.com. br biblioteca virtualbooks, livro de resenhas professor Ivan Carlo (Gian Danton) acesso 17 de julho 2014. 
Revista InterteXto / ISSN: 1981-0601

v. 9 , n. 2 (2016)

- Disponível http:// http://cienciaecultura.bvs.br/scielo.php?pid=S0009$\underline{67252006000200014 \& \text { script=sci arttext. Acesso } 01 \text { de outubro de } 2015 .}$

Artigo recebido em 30/11/2016

Artigo aceito em 27/12/2016 
Revista InterteXto / ISSN: 1981-0601

v. 9, n. 2 (2016)

\section{ANEXO I}

1.1 Capas

Ano de 1942

Graça e Beleza dezembro 1942

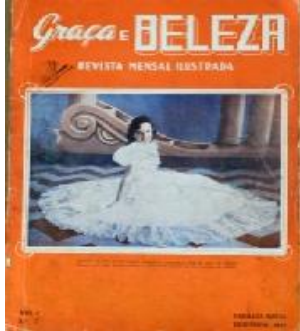

Ano de 1943

Graça e Beleza dezembro 1943

grapa: BELEEㅐㅐ

Ano de 1944

Graça e Beleza maio 1944

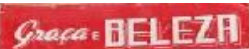

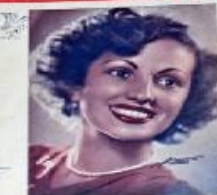

Ano de 1945

Graça e Beleza fevereiro 1945

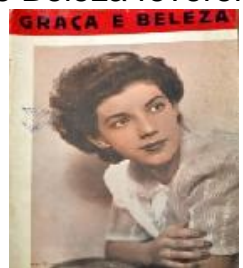




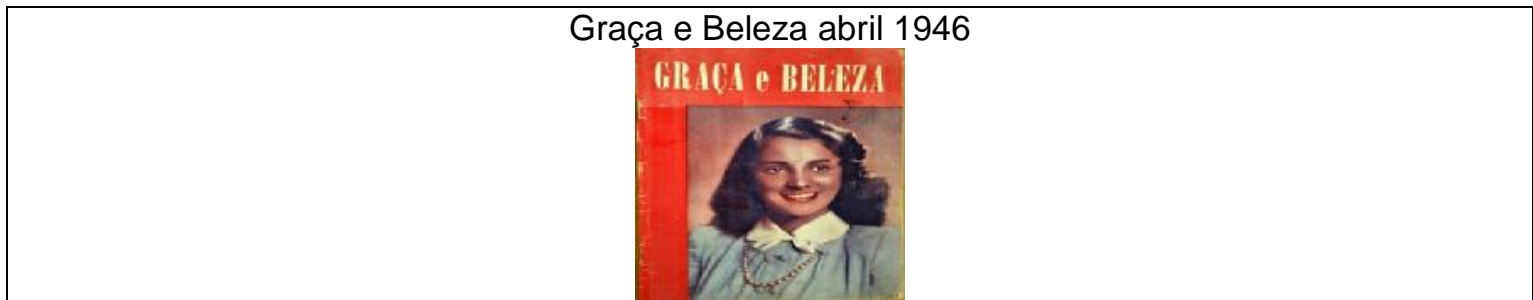

1.2

"Páginas das mãezinhas" e "Para alegrar a mulher"

Ano de 1942

Graça e Beleza dezembro 1942 (neste mês começa a pagina "Paginas das mãezinhas")

\begin{tabular}{|c|c|c|}
\hline \multirow{10}{*}{$\begin{array}{l}\text { "Páginas das mãezinhas" } \\
\mid \text { sagina das maveinhas }\end{array}$} & \multicolumn{2}{|c|}{ "Para alegrar a mulher" } \\
\hline & $\sqrt{\text { Sans afrequar a unillec } \because}$ & F- \\
\hline & Cronica & $\approx$ \\
\hline & 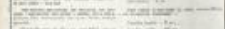 & 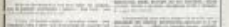 \\
\hline & $z^{2}$ & 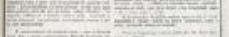 \\
\hline & Find & $-1-n_{0}$ \\
\hline & 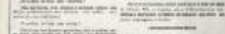 & DF \\
\hline & 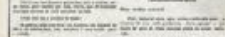 & $-12 \times$ \\
\hline & 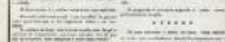 & 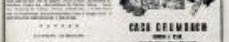 \\
\hline & $200=0$ & $1=-1$ \\
\hline
\end{tabular}

Ano de 1943 (neste ano a pagina "para alegrar a mulher" sofre alterações no desenho do titulo)

Graça e Beleza dezembro 1943

\begin{tabular}{|c|c|}
\hline "Páginas das mãezinhas" & "Para alegrar a mulher" \\
$\mid$\begin{tabular}{c|}
$\mid$ \\
-
\end{tabular} & \\
\hline
\end{tabular}


Ano de 1944

Graça e Beleza maio 1944

\begin{tabular}{|c|c|}
\hline $\begin{array}{c}\text { "Páginas das mãezinhas" } \\
\text { phatsa pas mäzanHas } \\
\end{array}$ & $\begin{array}{c}\text { "Para alegrar a mulher" (mudase novamente } 0 \\
\text { desenho do titulo) }\end{array}$ \\
\hline \\
\hline
\end{tabular}

Ano de 1945

Graça e Beleza fevereiro 1945

\begin{tabular}{|l|c|}
\hline "Páginas das mãezinhas" & "Para alegrar a mulher" \\
\hline & \\
\hline
\end{tabular}

Ano de 1946

Graça e Beleza abril 1946

\begin{tabular}{|c|c|}
\hline "Páginas das mãezinhas" & "Para alegrar a mulher" \\
Pagima das Mtareziulhus & \\
\hline
\end{tabular}


Revista InterteXto / ISSN: 1981-0601

v. 9, n. 2 (2016) 


\section{ANEXO II}

\section{AMOSTRA DO CORPUS}

\section{Páginas da mãezinha}

Campo semântico CASA

\begin{tabular}{|c|c|c|c|c|c|c|}
\hline Palavra & Valor da revista & $\begin{array}{l}\text { Pagina que se } \\
\text { encontra }\end{array}$ & Valor dicionário & Endereço & $\begin{array}{l}\text { Campo } \\
\text { semântico }\end{array}$ & Quantidade \\
\hline Ambiente & $\begin{array}{l}\text { Lugar onde a } \\
\text { criança vive }\end{array}$ & 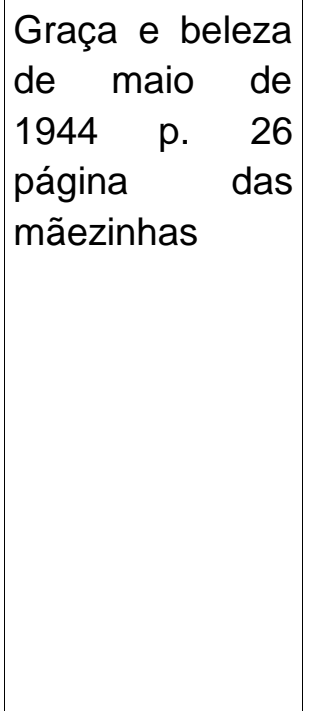 & $\begin{array}{l}\text { am.bi.en.te } \\
\text { sm } 10 \text { ar que respiramos ou } \\
\text { que nos cerca. } 2 \text { meio em } \\
\text { que vivemos ou em que } \\
\text { estamos:Ambiente físico, } \\
\text { social, familiar. A. de } \\
\text { campus, } \\
\text { extensa ou local com muitos } \\
\text { usuários conectados por } \\
\text { várias redes, como uma } \\
\text { universidade ou hospital. A. }\end{array}$ & $\begin{array}{l}\text { http://michaelis.uol.com.br } \\
\text { /moderno/portugues/index } \\
\text {.php?lingua=portugues- } \\
\text { portugues\&palavra=ambie } \\
\text { nte }\end{array}$ & Casa & \\
\hline
\end{tabular}


Revista InterteXto / ISSN: 1981-0601

v. 9 , n. 2 (2016)

\begin{tabular}{|c|c|c|c|c|c|}
\hline & & & $\begin{array}{l}\text { físico: parte do ambiente } \\
\text { humano que inclui fatores } \\
\text { puramente físicos (como solo, } \\
\text { clima etc.). }\end{array}$ & & \\
\hline Casa & $\begin{array}{l}\text { Lugar onde as } \\
\text { crianças moram }\end{array}$ & 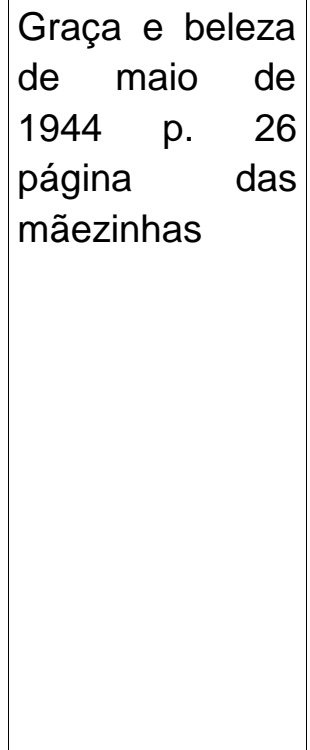 & $\begin{array}{l}\text { ca.sa } \\
\text { sf (lat casa) } 1 \text { Nome comum a } \\
\text { todas as construções } \\
\text { destinadas a moradia. } 2 \\
\text { Moradia, residência, vivenda. } \\
\text { Col: casaria, casario, taba } \\
\text { (para casas de índios). } 3 \\
\text { Estabelecimento, firma } \\
\text { comercial. } 4 \text { Família: Casa de } \\
\text { Bragança. } 5 \text { Subdivisão de } \\
\text { uma caixa, tabuleiro etc. } 6 \\
\text { Repartição pública: Casa da } \\
\text { Moeda. } 7 \text { Abertura em que } \\
\text { entram os botões do vestuário. }\end{array}$ & $\begin{array}{l}\text { http://michaelis.uol.com.br } \\
\text { /moderno/portugues/defini } \\
\text { cao/casa\%20_924854.htm } \\
\text { I }\end{array}$ & Casa \\
\hline Físico & $\begin{array}{l}\text { Lugar onde a } \\
\text { criança mora }\end{array}$ & \begin{tabular}{|lrr} 
Graça e beleza \\
de $\quad$ maio & de \\
1944 & p. & 26 \\
página & das \\
mãezinhas &
\end{tabular} & 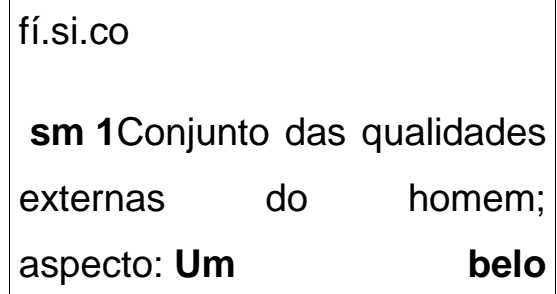 & $\begin{array}{l}\text { http://michaelis.uol.com.br } \\
\text { /moderno/portugues/index } \\
\text {.php?lingua=portugues- } \\
\text { portugues\&palavra=f\%ED }\end{array}$ & Casa \\
\hline
\end{tabular}




\section{Revista InterteXto / ISSN: 1981-0601}

v. 9 , n. 2 (2016)

\begin{tabular}{|c|c|c|c|c|c|}
\hline & & & 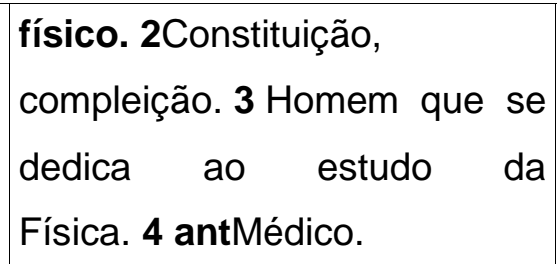 & sico & \\
\hline Janela & $\begin{array}{l}\text { Faz parte } \quad \text { da } \\
\text { estrutura física da } \\
\text { casa, por onde } \\
\text { geralmente a luz } \\
\text { entra. }\end{array}$ & 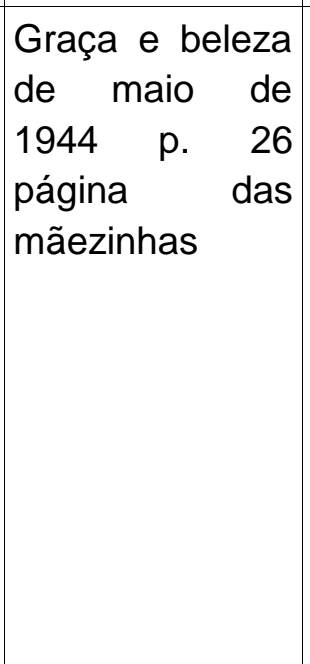 & $\begin{array}{l}\text { ja.ne.la } \\
\text { sf (lat vulg ianuella, } \\
\text { dim de ianua) } 1 \text { Abertura nas } \\
\text { paredes dos edifícios, para } \\
\text { deixar passar a luz e o } \\
\text { ar. } 2 \text { Caixilho de madeira, ferro } \\
\text { etc., com que se fecha essa } \\
\text { abertura. } \mathbf{3} \text { fam Abertura, } \\
\text { buraco ou rasgão na roupa ou } \\
\text { no calçado. }\end{array}$ & $\begin{array}{l}\text { http://michaelis.uol.com.br } \\
\text { /moderno/portugues/index } \\
\text {.php?lingua=portugues- } \\
\text { portugues\&palavra=janela }\end{array}$ & Casa \\
\hline Lar & $\begin{array}{l}\text { Onde a criança } \\
\text { mora com seus pais }\end{array}$ & 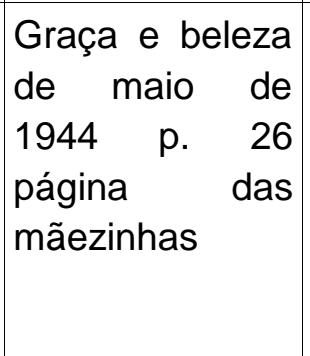 & $\begin{array}{l}\text { lar } \\
\text { sm (lat lare) } 1 \text { Lugar na } \\
\text { cozinha em que se acende o } \\
\text { fogo; lareira; fogão. } 2 \\
\text { Superfície do forno onde se }\end{array}$ & $\begin{array}{l}\text { http://michaelis.uol.com.br } \\
\text { /moderno/portugues/index } \\
\text {.php?lingua=portugues- } \\
\text { portugues\&palavra=lar }\end{array}$ & Casa \\
\hline
\end{tabular}


Revista InterteXto / ISSN: 1981-0601

v. 9 , n. 2 (2016)

\begin{tabular}{|c|c|c|c|c|c|}
\hline & & & $\begin{array}{l}\text { põe o pão para cozer. } 3 \text { Face } \\
\text { inferior do pão, que fica } \\
\text { assente sobre a superfície do } \\
\text { forno. } 4 \text { Torrão natal; pátria. } 5 \\
\text { Casa de habitação. } 6 \text { Família. } \\
\text { sm pl Nome dos deuses } \\
\text { familiares e protetores do lar } \\
\text { doméstico, entre os romanos e } \\
\text { etruscos. L. doméstico: a casa } \\
\text { da família. }\end{array}$ & & \\
\hline Luz & \begin{tabular}{ll|} 
llumina & os \\
ambientes
\end{tabular} & 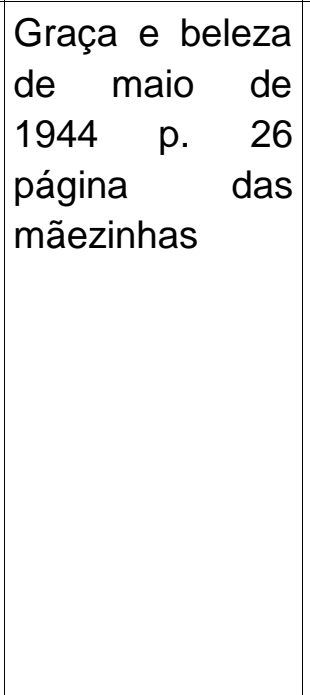 & 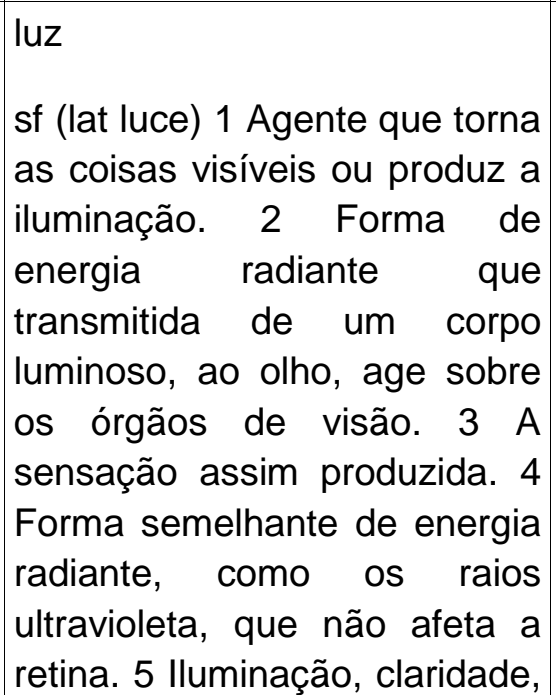 & $\begin{array}{l}\text { http://michaelis.uol.com.br } \\
\text { /moderno/portugues/index } \\
\text {.php?lingua=portugues- } \\
\text { portugues\&palavra=luz }\end{array}$ & Casa \\
\hline
\end{tabular}


Revista InterteXto / ISSN: 1981-0601

v. 9 , n. 2 (2016)

\begin{tabular}{|c|c|c|}
\hline & 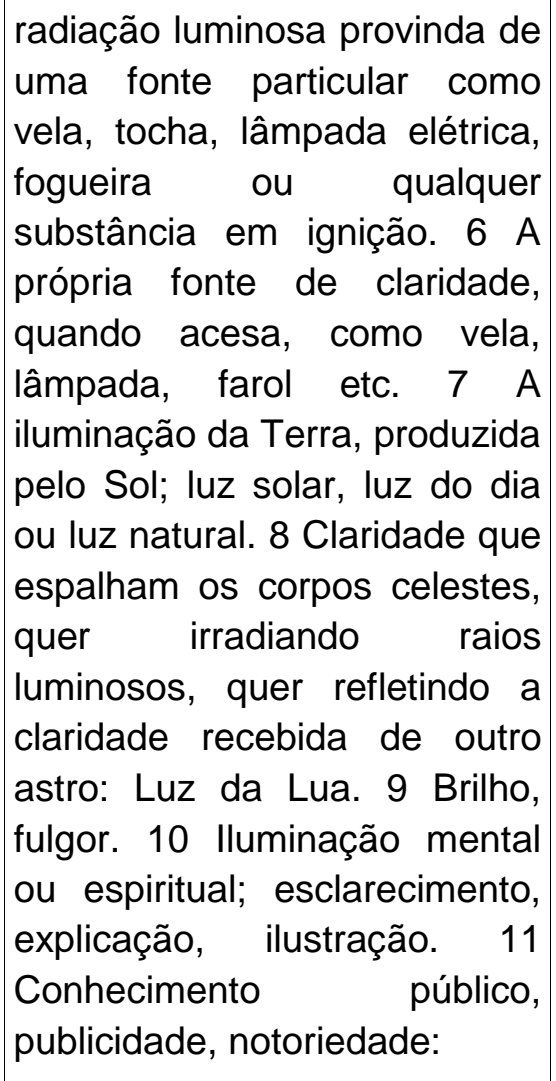 & \\
\hline Total & & 0 \\
\hline
\end{tabular}




\section{Para alegrar a mulher}

Campo semântico: beleza

\begin{tabular}{|c|c|c|c|c|c|}
\hline Pintura & $\begin{array}{l}\text { Ato de pintar assim } \\
\text { as mulheres fazem } \\
\text { suas maquiagens }\end{array}$ & 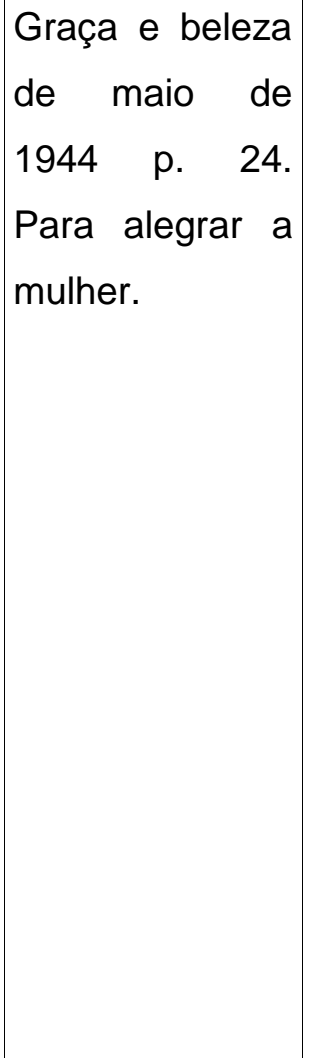 & $\begin{array}{l}\text { pin.tu.ra } \\
\text { sf (lat vulg *pinctura, por } \\
\text { pictura) } 1 \text { Ramo da arte que, } \\
\text { por meio de linhas e cores, } \\
\text { representa sobre uma } \\
\text { superfície as concepções do } \\
\text { artista. } 2 \text { Profissão de pintar. } 3 \\
\text { Obra executada por pintor; } \\
\text { quadro. } 4 \text { Descrição } \\
\text { minuciosa. } 5 \text { Pessoa ou coisa } \\
\text { muito bonita e perfeita. } 6 \text { Cor } \\
\text { aplicada a um objeto. } 7 \\
\text { Embelezamento do rosto por } \\
\text { meio de pós e cosméticos. } 80 \\
\text { conjunto de cosméticos e pós } \\
\text { para esse embelezamento. }\end{array}$ & $\begin{array}{l}\text { http://michaelis.uol.com.br } \\
\text { /moderno/portugues/defini } \\
\text { cao/pintura\%20_1021875. } \\
\text { html }\end{array}$ & Beleza \\
\hline
\end{tabular}




\begin{tabular}{|c|c|c|c|c|c|}
\hline Plástica & $\begin{array}{l}\text { Cirurgia para } \\
\text { correção de alguma } \\
\text { parte do carpo }\end{array}$ & $\begin{array}{l}\text { Graça e beleza } \\
\text { de dezembro de } \\
1942 \text { p. } 34 . \\
\text { Para alegrar a } \\
\text { mulher }\end{array}$ & $\begin{array}{l}\text { plás.ti.ca } \\
\text { sf (gr plastiké) } 1 \text { Arte de } \\
\text { plasmar. } 2 \text { Cir } \\
\text { reconstituir } \text { uma } \quad \text { parte } \\
\text { arruinada ou deformada do } \\
\text { corpo humano: Cirurgia } \\
\text { plástica. } 3 \text { Conformação geral } \\
\text { do corpo humano. }\end{array}$ & $\begin{array}{l}\text { http://michaelis.uol.com.br } \\
\text { /moderno/portugues/index } \\
\text {.php?lingua=portugues- } \\
\text { portugues\&palavra=pl\%E1 } \\
\text { stica }\end{array}$ & Beleza \\
\hline Pó & \begin{tabular}{|lrr} 
Raspa & a & pedra \\
hume & para & colocar \\
nos & machucados \\
nas & unhas & para \\
curar. & &
\end{tabular} & $\begin{array}{l}\text { Graça e beleza } \\
\text { de dezembro de } \\
1942 \text { p. } 34 . \\
\text { Para alegrar a } \\
\text { mulher }\end{array}$ & $\begin{array}{l}\text { pó } \\
\text { sm (lat *pulu, de *pulvu por } \\
\text { pulve) } 1 \text { Finíssimas partículas } \\
\text { de terra seca ou de qualquer } \\
\text { outra substância; poeira. } 2 \\
\text { Substância constituída de } \\
\text { partículas tenuíssimas de } \\
\text { qualquer coisa sólida que se } \\
\text { submeteu à moagem, } \\
\text { trituração etc.: Pó de vidro, pó } \\
\text { de café. } 3 \text { Polvilho. } 4 \text { Os } \\
\text { resíduos materiais de um } \\
\text { corpo após a morte: Pó és e }\end{array}$ & $\begin{array}{l}\text { http://michaelis.uol.com.br } \\
\text { /moderno/portugues/defini } \\
\text { cao/po\%20_1024024.html }\end{array}$ & Beleza \\
\hline
\end{tabular}


Revista InterteXto / ISSN: 1981-0601

v. 9 , n. 2 (2016)

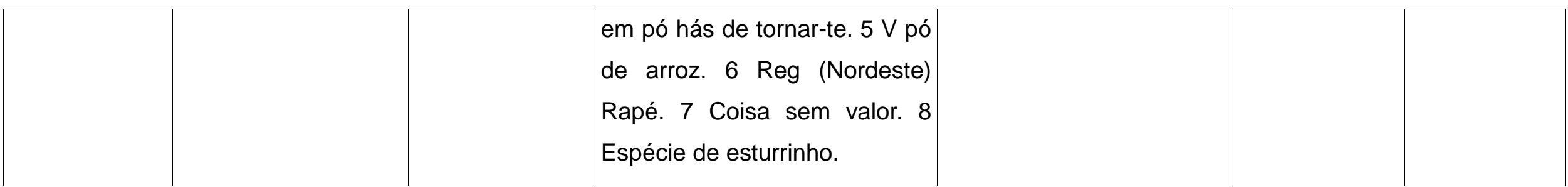

